WORLD VIEW

\title{
Distribution of intraocular pressure in healthy Iranian individuals: the Tehran Eye Study
}

H Hashemi, A H Kashi, A Fotouhi, K Mohammad

Br J Ophthalmol 2005;89:652-657. doi: 10.1136/bjo.2004.058057

Series editors: W V Good and S Ruit

See end of article for authors' affiliations

......................

Correspondence to: Akbar Fotouhi, MD, PhD, No 6, Babak Bahrami Street, Valiasr Avenue, 19686-55751, Tehran Iran;

afotouhi@sina.tums.ac.ir

Accepted for publication 1 January 2005
Aim: To provide data on the distribution of intraocular pressure (IOP) in an Iranian population.

Methods: Through a population based, cross sectional study, 4565 Tehran citizens were studied in the Tehran Eye Study. The findings from the participants $(n=3834)$ aged 10 years and older free of glaucoma diagnosis or suspicion who had undergone applanation tonometry examination are presented. All participants received a standardised protocol including applanation tonometry, fundus examination, demographic data, and an interview. IOP measurement was used to evaluate its distribution by age, sex, and some eye parameters.

Results: Mean (SD) IOP was 14.5 (2.6) $\mathrm{mm} \mathrm{Hg}$ in the total population, 14.4 (2.7) in men, and 14.5 (2.5) in women. Mean (SD) IOP in people $\geqslant 40$ years was 15.1 (2.9) $\mathrm{mm} \mathrm{Hg}$. IOP increased significantly with age and cup:disc ratio except for a fall in old age. This relation was also observed when individuals without diabetes or hypertension history were analysed. IOP increased with darker eye pigmentation except for blue/grey eyes. There was a non-linear increase in IOP from emmetropic to high myopic eyes.

Conclusion: Age, iris colour, and cup:disc ratio were related to IOP but not to sex. The distribution of IOP in this study was different from various other studies in different geographical regions and it seems advisable to employ a geographical approach to normal IOP interpretation. ntraocular pressure (IOP) is known to be a glaucoma risk factor. ${ }^{1-5}$ Most published studies on the association between glaucoma and IOP with risk factors have focused on European and American populations and a few on south east Asians. The results show a clear association of IOP and glaucoma prevalence with ethnicity. ${ }^{15-10}$ Furthermore, studies on similar ethnic populations have not given consistent results. For example, mean IOP in a Japanese survey was reported to be $13.3 \mathrm{~mm} \mathrm{Hg}$ for normal people aged over 40 years ${ }^{11}$ while in a Korean study despite enrolling younger people (over 20 years) mean IOP was reported to be $15.5 \mathrm{~mm} \mathrm{Hg} .{ }^{12}$ With respect to the differences in IOP assessments in different ethnic populations, and considering IOP as a traditional still in-use screening means of glaucoma detection, ${ }^{13}{ }^{14}$ it would be necessary to implement studies on IOP distribution of different populations to determine its normal range and distribution.

Determining IOP distribution in different ethnic populations and factors associated with it can also be helpful in understanding the difference in glaucoma prevalence and its associated factors in different areas of the world. ${ }^{13}$ Many factors have been reported to influence IOP. Age, sex, iris colour, diabetes, and blood pressure are the most frequent reported factors, ${ }^{5} 810131516$ but the results have been inconsistent.

To our knowledge, there have been few studies on the assessment of IOP in a central Asian or Middle Eastern population. This study evaluates IOP distribution in an Iranian population.

\section{MATERIALS AND METHODS}

\section{Participants' enrolment}

The Tehran Eye Study (TES) is a population based cross sectional study. Detailed descriptions of the methods of this study have been published previously ${ }^{17}{ }^{18}$ and are summarised here. The sampling strategy of the study followed a stratified cluster sampling procedure with proportional allocation within strata. The survey target population comprised non-institutionalised urban citizens of all ages, who resided in Tehran city in 2002.

\section{Eye examination protocol}

The standardised protocol for all participants in the study included an interview, height and weight measurement, and an extensive eye examination. The standardised interview obtained demographic details, medical and family history, and information about eye diseases risk factors.

Refraction was measured by optometrists for all participants using a Topcon automated refractometer (Topcon KR 8000, Topcon Corporation, Tokyo, Japan), according to the instruction manual. For practical purposes of this article myopia and hyperopia were defined as spherical equivalents of less than -0.5 dioptre and more than 0.5 dioptre. Low, moderate, and high hyperopia was defined as spherical equivalents more than 0.5 dioptres, more than 3 dioptres, and more than 5 dioptres. A similar definition was used for myopia. ${ }^{19} 20$ Iris colour was determined by viewing the participant's iris with the pupil undilated using a penlight. The colour was compared to a colour standard developed on the basis of the standards used in the Beaver Dam Eye Study. IOP was measured using a Goldmann applanation tonometer. A drop of tetracaine was instilled in each eye of the participant and tear was stained with fluorescein. The tonometer was swung into place on the slit lamp, the blue filter put into place, and the beam width opened to its fullest height. The beam angle was about 45-60 degrees to the side of the tonometer and illuminated the end of the prism head. If IOP was $>30 \mathrm{~mm} \mathrm{Hg}$, it was rechecked after dilatation. If IOP was $>40 \mathrm{~mm} \mathrm{Hg}$, the ophthalmologist prescribed appropriate treatment for the participant and informed him/her about the disease. Then all participants underwent a retinal examination first using direct ophthalmoscopy followed by indirect ophthalmoscopy. The retina was examined systematically to ensure that no lesions are missed. The examiner

Abbreviations: IOP, intraocular pressure; TES, Tehran Eye Study 

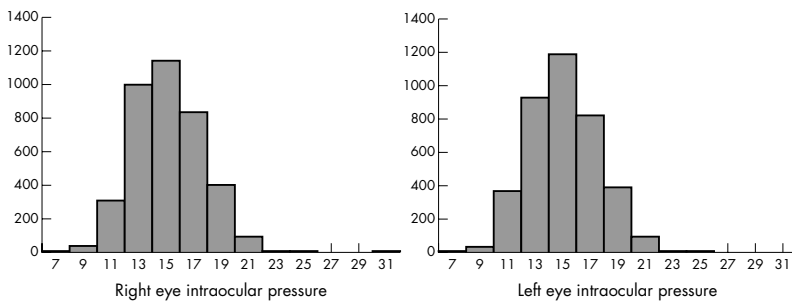

Figure 1 Distribution of intraocular pressure in healthy individuals.

inspected the optic disc assessing disc size, colour, vascularity, and degree of cupping.

In order to perform analysis on healthy eyes with no suspicion or evidence of glaucoma, participants with a history of self reported glaucoma, glaucomatous eye surgery, people who were using glaucoma medication in either eye, those with cup:disc ratio more than 5, or cup:disc asymmetry more than 2 were excluded from analysis.

The research and ethics committee of the Noor Vision Correction Centre and ethics committee of the National Research Centre for Medical Sciences approved the study. All subjects included in this study were informed about the project and the procedures in their native language before being enrolled. The participants' agreement for examination was obtained verbally.

\section{RESULTS}

Between August and December 2002, 4565 of the 6497 eligible individuals in the sample completed the interview and participated in ophthalmic examinations (a participation rate of $70.3 \%$ ). Applying criteria to healthy people, mentioned in the methods, excluded 41 individuals from study. Furthermore, as IOP measurement was difficult in young children and this group had mostly high missing rates on IOP measurements, we have presented data on individuals $\geqslant 10$ years. This resulted in the additional exclusion of 555 children from analysis. IOP data were not measured in 136 participants. Data on the remaining 3833 people are presented. Mean (SD) age was 33.6 (17.3) years and 2267 were women $(59.1 \%)$. Diabetes, high blood pressure, and heart attack history were present in 183 (4.8\%), 259 (6.8\%), and $140(3.7 \%)$ individuals, respectively. In all, 118 participants $(3.1 \%)$ smoked cigars or pipes and $390(10.2 \%)$ were

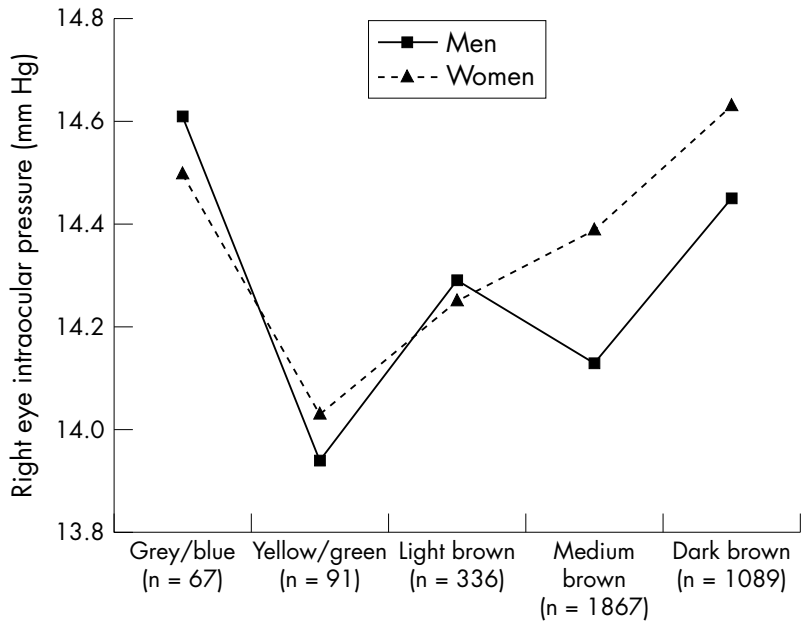

Figure 2 Intraocular pressure by iris colour by sex in participants without diabetes or hypertension.

current cigarette smokers. IOP distribution in right and left eyes is shown in figure 1 . IOP $>21 \mathrm{~mm} \mathrm{Hg}$ was observed in $0.3 \%$ and $0.4 \%$ of people in their right and left eyes respectively. There was no statistically significant difference between mean IOP of right and left eyes (14.47 $\mathrm{mm} \mathrm{Hg}$ and $14.48 \mathrm{~mm} \mathrm{Hg}$, respectively, $\mathrm{p}$ value $>0.05)$. The Pearson correlation coefficient for right and left eye measurements was 0.85 ( $\mathrm{p}$ value $<0.001$ ). As there was no significant difference between right and left eyes measurements, data in the following sections are based on right eye measurements. Mean (SD) IOP in people $\geqslant 40$ years was 15.1 (2.9) $\mathrm{mm} \mathrm{Hg}$ and $0.9 \%$ of them had IOP $>21 \mathrm{~mm} \mathrm{Hg}$.

Age and sex specific IOP in participants is given in table 1 . A nearly steady increase from childhood into adulthood is evident in both sexes except for a decrease in mean IOP in women over 70 years and men over 80 years (data not shown). As the prevalence of a self reported history of diabetes and hypertension was different in different age groups, mean (SD) IOP in people without diabetes or hypertension has also been presented. The pattern is still observed in men and women without diabetes or hypertension. Figures 2 and 3 show distribution of IOP with respect to right iris colour and right eye spherical equivalent categories

Table 1 Age and sex specific distribution of IOP $(\mathrm{mm} \mathrm{Hg})$ in all healthy Tehran Eye Study participants $(n=3833)$ and in healthy individuals without history of diabetes or hypertension $(n=3457)$

\begin{tabular}{lllll}
\hline & $\begin{array}{l}\text { Age group } \\
\text { (years) }\end{array}$ & $\begin{array}{l}\text { Women } \\
\text { Mean (SD) (n) }\end{array}$ & $\begin{array}{l}\text { Men } \\
\text { Mean (SD) (n) }\end{array}$ & $\begin{array}{l}\text { All } \\
\text { Mean (SD) (n) }\end{array}$ \\
\hline All healthy individuals & $10-19.9$ & $14.1(2.2)(566)$ & $13.6(2.2)(503)$ & $13.9(2.2)(1069)$ \\
& $20-29.9$ & $14.1(2.1)(490)$ & $14.1(2.5)(236)$ & $14.1(2.2)(726)$ \\
& $30-39.9$ & $14.6(2.3)(413)$ & $14.4(2.5)(246)$ & $14.6(2.4)(659)$ \\
& $40-49.9$ & $15.1(2.6)(398)$ & $15.1(2.7)(212)$ & $15.1(2.7)(610)$ \\
& $50-59.9$ & $15.0(3.1)(233)$ & $14.8(3.1)(175)$ & $14.9(3.1)(408)$ \\
& $60-69.9$ & $15.4(2.9)(102)$ & $15.5(3.3)(112)$ & $15.5(3.1)(214)$ \\
& $7=70$ & $14.9(3.2)(65)$ & $15.3(2.7)(82)$ & $15.1(2.9)(147)$ \\
Healthy individuals without diabetes or & Total & $14.5(2.5)(2267)$ & $14.4(2.7)(1566)$ & $14.5(2.6)(3833)$ \\
hypertension & $10-19.9$ & $14.1(2.2)(562)$ & $13.6(2.2)(501)$ & $13.9(2.2)(1063)$ \\
& $20-29.9$ & $14.0(2.1)(487)$ & $14.1(2.5)(234)$ & $14.1(2.3)(721)$ \\
& $30-39.9$ & $14.6(2.3)(393)$ & $14.4(2.5)(236)$ & $14.5(2.4)(629)$ \\
& $40-49.9$ & $15.2(2.6)(334)$ & $14.9(2.8)(190)$ & $15.1(2.7)(524)$ \\
& $50-59.9$ & $14.7(2.8)(172)$ & $14.8(3.0)(142)$ & $14.8(2.9)(314)$ \\
& $60-69.9$ & $15.1(2.6)(46)$ & $15.1(3.1)(71)$ & $15.1(2.9)(117)$ \\
& $>=70$ & $14.2(3.1)(26)$ & $15.4(2.7)(63)$ & $15.1(2.9)(89)$ \\
& Total & $14.4(2.4)(2020)$ & $14.3(2.6)(1437)$ & $14.4(2.5)(3457)$
\end{tabular}




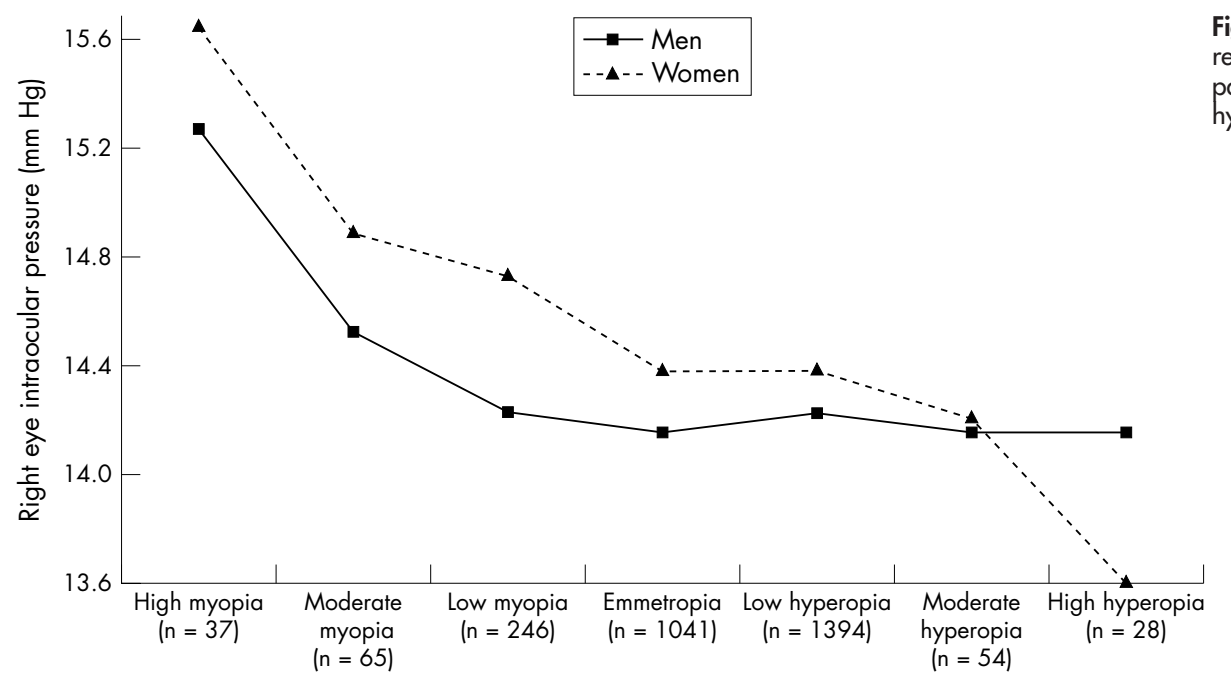

Figure 3 Intraocular pressure by refractive error categories by sex in participants without diabetes or hypertension.

of myopia and hyperopia separately in men and women. As iris colour and eye spherical equivalents were both related to IOP and hypertension or diabetes, the figures were restricted to people without diabetes or hypertension. Table 2 represents IOP data with respect to increasing values of cup to disc ratio in people older than 50 years and in younger individuals.

\section{DISCUSSION}

The role of IOP and its relation to glaucoma has been the focus of scientific inquiry during past decades. While glaucoma definition now relies more on structural and functional damage, ${ }^{21}$ IOP is still in use as a simple, accessible, and inexpensive method for suspects' referral by general practitioners. Many studies have documented increasing frequency of glaucoma cases or glaucomatous visual field defects with increasing IOP values ${ }^{22} 23$ and especially values over 20-23 $\mathrm{mm} \mathrm{Hg}^{4}{ }^{-11}$; however, a recent study on Hispanic subjects has attributed this relation as weak and specific to IOP over $30 \mathrm{~mm} \mathrm{Hg}^{24}$

\section{IOP distribution}

IOP distribution in left and right eyes has been shown in figure 1. It is like the well known Gaussian-like distribution with little right skewness found in other studies. ${ }^{25-27}$ Some researchers have proposed that IOP has a normal distribution up to the age of 20-30 years and then is skewed because of the small number of people who will develop high IOP. ${ }^{25}$ According to our study, the standard deviation of IOP distribution and its skewness changes slightly from 1019 years up to 60-69 years (data not shown). In fact, IOP values in ages over 60 were associated with least skewness.
The previous observation might be a consequence of adding definite or suspected glaucoma cases to normal people.

\section{Mean and normal range of IOP}

Table 3 summarises results of different studies on IOP in various geographic areas and racial groups. There is substantial discrepancy between different studies and even when these studies were performed on populations within similar geographic locations or racial groups. For example, studies by Lee $e t a l^{12}$ and Shiose $e t a l^{11}$ performed on Korean and Japanese populations present considerable variations in their results in terms of mean IOP values and IOP associations. The different prevalences of high IOP/glaucoma risk factors may be an explanation that needs proper reports of their frequency, which is lacking in most of the literature.

If we use the conventional approach of mean (+2 SD) in defining the upper limit of normal IOP $^{422} 27$; then according to the study by Shiose et al, this cut off would be $19.64 \mathrm{~mm} \mathrm{Hg}$, while according to the Baltimore Eye Study it would be $23.87 \mathrm{~mm} \mathrm{Hg}$ (or $24.36 \mathrm{~mm} \mathrm{Hg}$ for a black population). In our study, the upper limit of normal IOP was $19.7 \mathrm{~mm} \mathrm{Hg}$ for people $\geqslant 10$ years and $20.8 \mathrm{~mm} \mathrm{Hg}$ for people $\geqslant 40$ years.

Given the fact that IOP distribution is different in different races and residents of different locations then we propose a geographical or racial approach for defining the normal IOP range.

\section{IOP and age}

In this study, increasing age was associated with increasing IOP values in males and females, both in total population and in people without diabetes or hypertension.

\begin{tabular}{|c|c|c|c|}
\hline \multirow[b]{2}{*}{ Vertical CDR } & \multicolumn{3}{|c|}{ Mean (SD) IOP $(\mathrm{mm} \mathrm{Hg})(\mathrm{n})$} \\
\hline & $\begin{array}{l}\text { Age }<50 \text { years } \\
(n=2932)\end{array}$ & $\begin{array}{l}\text { Age } \geqslant 50 \text { years } \\
(n=735)\end{array}$ & $\begin{array}{l}\text { All ages } \\
(n=3667)\end{array}$ \\
\hline 1 & $14.0(2.5)(239)$ & $14.3(3.1)(30)$ & $14.0(2.6)(269)$ \\
\hline 2 & $14.1(2.4)(1530)$ & 15.1 (3.0) (325) & $14.3(2.5)(1855)$ \\
\hline 3 & $14.6(2.3)(1025)$ & $15.1(2.9)(321)$ & $14.7(2.5)(1346)$ \\
\hline 4 & $14.5(2.3)(115)$ & $16.0(3.7)(51)$ & $15.0(2.9)(166)$ \\
\hline 5 & $14.9(2.3)(23)$ & $16.5(4.3)(8)$ & $15.3(2.9)(31)$ \\
\hline
\end{tabular}




\begin{tabular}{|c|c|c|c|c|c|c|c|c|}
\hline Study & Country, year & Setting & Age (years) & $\begin{array}{l}\text { Measurement tool } \\
\text { for IOP }\end{array}$ & $M / F$ & Group & IOP (mean (SD)* & $\begin{array}{l}\mathrm{OH} \\
(\%)^{*}\end{array}$ \\
\hline Shiose 11 & Japan, 1988-9 & Population based & $\geqslant 40$ & $\mathrm{NCT} \dagger$ & $3031 / 5095$ & $\begin{array}{l}M \\
F \\
N l \\
T\end{array}$ & $\begin{array}{l}13.1(3.0) \neq \\
13.4(3.0) \neq \\
13.3(3.0) \\
13.4(3.1)\end{array}$ & $\begin{array}{l}1.8 \S \\
1.3 \S \\
\text { NR } \\
1.4 \S\end{array}$ \\
\hline \multirow[t]{2}{*}{ Weih $^{10} 40$} & Australia, 1992-6 & $\begin{array}{l}\text { Population based, } \\
\text { cross sectional }\end{array}$ & $\geqslant 40$ & $\begin{array}{l}\text { Tono-Pen (+ } \\
\text { Goldmann) }\end{array}$ & $2230 / 2514$ & $\mathrm{Nl}$ & 14.5 (3.1) t† & 1.5 \\
\hline & & & & & & $\mathrm{T}$ & $14.7(3.5)$ & 2.8 \\
\hline \multirow[t]{4}{*}{ Egna-Neumarkt $t^{6}$} & Italy, NR & $\begin{array}{l}\text { Cross sectional, } \\
\text { epidemiological }\end{array}$ & $>40$ & Goldmann & $1882 / 2415$ & $M$ & $15.1(2.8)$ & 2.7 \\
\hline & & & & & & $\mathrm{F}$ & $14.9(2.6)$ & 1.6 \\
\hline & & & & & & $\mathrm{Nl}$ & & NR \\
\hline & & & & & & $\mathrm{T}$ & NR & 2.1 \\
\hline \multirow[t]{3}{*}{$\operatorname{Lee}^{12}$} & Korea, $1997-2000$ & $\begin{array}{l}\text { Healthy people } \\
\text { examined at a health } \\
\text { centre }\end{array}$ & $20-84$ & NCT & $6684 / 6528$ & M & $16.1(3.2)$ & 6.1 \\
\hline & & & & & & $\mathrm{F}$ & $15.1(2.9)$ & 2.5 \\
\hline & & & & & & $\mathrm{Nl}$ & $15.5(3.1)$ & 4.3 \\
\hline \multirow{3}{*}{ Blue Mountains ${ }^{4}$} & Australia, 1992-4 & Population based & 49-97 & Goldmann & & $M$ & NR & 3.8 \\
\hline & & & & & & $\mathrm{F}$ & NR & 3.6 \\
\hline & & & & & & $\mathrm{T}$ & $16.1(2.9) \dagger$ & 3.7 \\
\hline Baltimore $^{5}$ & US, 1985-8 & Population based & $\geqslant 40$ & Goldmann & & White & $17.2(3.3)$ & NR \\
\hline Rotterdam ${ }^{30}$ & Netherlands, 1991-3 & Population cohort & $\geqslant 55$ & Goldmann & $1226 / 1836$ & T & 14.6 (NR) & 2.2 \\
\hline \multirow{3}{*}{ Beaver Dam ${ }^{8}$} & US, NR & Population based & $43-84$ & Goldmann & $2135 / 2721$ & M & $15.3(3.4)$ & 4.4 \\
\hline & & & & & & $\mathrm{F}$ & $15.5(3.3)$ & 4.7 \\
\hline & & & & & & $\mathrm{Nl}$ & $15.3(3.2)$ & NR \\
\hline \multirow[t]{4}{*}{ Barbados $^{13}$} & Barbados, 1988-92 & Population based & $40-84$ & & & $M \ddagger$ & $17.6(3.4)$ & NR \\
\hline & & & & & & $\mathrm{Ff}$ & $18.0(3.6)$ & NR \\
\hline & & & & & & & $17.8(3.5)$ & \\
\hline & & & & & & Black & $18.1(4.8)$ & 12.8 \\
\hline \multirow[t]{2}{*}{ Wallace $^{15}$} & Jamaica, 1965 & Epidemiological study & $35-74$ & Goldmann & $232 / 342$ & $M$ & $16.8(2.8) \dagger \neq$ & $\begin{array}{l}\mathrm{NR} \\
\mathrm{NR}\end{array}$ \\
\hline & & & & & & $\mathrm{T}$ & & 7.4 \\
\hline Rotchford $^{26}$ & South.Africa, NR & $\begin{array}{l}\text { Population based, } \\
\text { cross sectional }\end{array}$ & $>40$ & $\begin{array}{l}\text { Goldmann + Tono- } \\
\text { Pen }\end{array}$ & $-280 / 725$ & $\mathrm{Nl}$ & $13.9(3.4)$ & 3.5 \\
\hline \multirow[t]{3}{*}{ Framingham ${ }^{29}$} & US, 1973-5 & Population cohort & $52-85$ & Goldmann & $1030 /$ & M & $17.0(4.0)$ & NR \\
\hline & & & & & 1415 & $\mathrm{~F}$ & $17.1(4.1)$ & NR \\
\hline & & & & & & $\mathrm{T}$ & $17.0(4.1)$ & NR \\
\hline \multirow[t]{2}{*}{ TES } & Iran, 2002 & $\begin{array}{l}\text { Population based, } \\
\text { cross sectional }\end{array}$ & $\geqslant 10$ & Goldmann & $1566 /$ & $M$ & $14.4(2.7)+ \pm$ & $0.4^{* *}$ \\
\hline & & & & & 2267 & $\begin{array}{l}\mathrm{F} \\
\mathrm{Nl}\end{array}$ & $\begin{array}{l}14.5(2.5)+ \pm \\
14.5(2.6)+\end{array}$ & $\begin{array}{l}0.4^{* *} \\
0.4^{* *}\end{array}$ \\
\hline \multicolumn{9}{|c|}{$\begin{array}{l}\text { M/F, number of men/women; OH, ocular hypertension (IOP }>21 \\
\text { tonometer; NR, not reported; US, United States; TES, Tehran Eye St } \\
\text { *Figures were rounded to one decimal point. } \\
\text { †Right eyes IOP reported. } \\
\text { †IOP measurements on healthy eyes excluding glaucomatous eyes. } \\
\text { sIOP }>20 \mathrm{~mm} \text { Hg. } \\
\text { t†ln healthy non-hypertensive eyes. } \\
\text { † } 15.1 \text { (2.9) mm Hg for normal men, women, or people } \geqslant 40 \text { years. } \\
{ }^{*} 0.9 \text { for men, women, or people } \geqslant 40 \text { years (and } 1.8 \% \text { IOP }>20\end{array}$} \\
\hline
\end{tabular}

Most European and American studies have reported a positive association of age with IOP. ${ }^{61328} 29$ In some, this relation was not significant. ${ }^{30}$ Korean and Japanese studies, ${ }^{11} 122731$ and recently an Australian study, ${ }^{10}$ have reported a negative association. In their article, Shiose et $\mathrm{l}^{27}$ proposed two reasons to account for such an observation: (1) IOP decreases with age longitudinally, and (2) even in European and American studies IOP is constant in most people and IOP increases with age. Our study data suggest that IOP distribution skewness does not increase with age; however, there is a trend of increasing standard deviation with age ${ }^{25}$ (table 2). In fact, ages over 60 were associated with lower skewness. A longitudinal decrease of IOP with age indicated in the article by Shiose et al is from two longitudinal studies on IOP values in patients with ocular hypertension and glaucoma without treatment. Decreasing mean IOP over time is expected according to the rule of regression towards mean and cannot be attributed to an IOP decrease with age. It can also be assumed to be a cohort effect, but further studies are needed to evaluate the latter theory. A recent longitudinal study by Hennis et al, ${ }^{7}$ on 2996 healthy people, reported a $2.5 \mathrm{~mm} \mathrm{Hg}$ increase in mean IOP during 4 years of follow up, which favours the theory of an IOP increase with age.

In contrast with some European and American studies that attributed age related IOP increase to ages over 40 years, ${ }^{25} 28$ the results of this study show that an IOP increase with age is evident from adolescence. This finding is compatible with results of other studies. ${ }^{32}{ }^{33}$ In our study, mean IOP increase from $10-19$ years to $30-39$ years is $0.8 \mathrm{~mm} \mathrm{Hg}$, while the increase from 30-39 years to $50-59$ years is only $0.3 \mathrm{~mm} \mathrm{Hg}$.

\section{IOP and sex}

In our study hypertension and diabetes frequency were higher among women and, after adjusting for them, the relation between IOP and sex was not significant.

Similarly most studies that have used a multivariable model to evaluate simultaneous relations of risk factors and confounder adjustment, have reported an insignificant relation between sex and $\mathrm{IOP}^{10}{ }^{32}$ or categorised sex with variables of little importance. ${ }^{16}$ 


\section{Iris colour and IOP}

A linear relation has been found between IOP and the amount of iris pigmentation in some studies ${ }^{34} 35$ and rejected in other studies. ${ }^{8}$ Another study has found this relation to be significant but not linear. Eyes with blue/grey/green colour had higher IOP in comparison with green/light brown eyes. ${ }^{10}$ Our data show a clear increasing pattern of IOP with iris pigmentation in yellow/green to dark brown eyes, but IOP values in grey/blue eyes were very high and around the values obtained for dark brown eyes (fig 2). High IOP values in blue/ grey eyes were observed even after adjusting for age and sex. We could not find any prominent IOP risk factor in blue/grey eyes (including ethnicity) to account for the high observed IOP.

\section{IOP and refraction}

Figure 3 clearly shows a decreasing pattern of IOP with increasing refraction spherical equivalents. As age is related both to refraction and IOP, we evaluated the relation in separate age groups of 10-39, 40-59, and over 59 years. The aforementioned trend was still evident. In the literature spherical equivalent refraction was observed to have a significant negative relation with IOP in regression analysis. ${ }^{810}$

\section{IOP and cup:disc ratio}

Table 2 provides data of IOP with respect to vertical cup:disc ratio. In the younger age group, there is a total increase of $0.9 \mathrm{~mm} \mathrm{Hg}$ in IOP while cup:disc ratio increases from 1 to 5 . In people older than 50 years, the total increase in IOP is $1.2 \mathrm{~mm} \mathrm{Hg}$ for a cup:disc ratio increase from 1 to 5 which is $30 \%$ more in comparison with the younger age group. There are conflicting reports on the relation between cup:disc ratio and IOP. Many authors have reported a positive association of IOP with cup:disc ratio, ${ }^{13} 23243637$ but some have found no association. Insignificant results come from the WESDR project on diabetic eyes with the view that diabetic eyes are more prone to cup development, ${ }^{38} 39$ while studies with significant results mostly are from healthy individuals. In Barbados, the relation was stronger in people younger than 70 years, while the results of our study show a more pronounced increase in IOP with advancing cup:disc ratios in people older than 50 years. Two studies that implemented a multiple regression model to adjust for the effects of confounders found the association still to be significant. ${ }^{13}{ }^{23} \mathrm{~A}$ cup:disc ratio relation with IOP was significant in our study after adjusting for age, sex, refraction, diabetes, and hypertension.

\section{Conclusion}

IOP distribution is slightly skewed to the right. This skewness is evident from adolescence to old age. IOP values increase with advancing age and this increase is observed from adolescence. IOP values increase with increasing cup:disc ratios and iris pigmentation (except for blue eyes) and with decreasing corneal spherical equivalents but is not related to sex. Mean and distribution of IOP in our study is different from other studies in different geographical regions. We think it seems advisable to employ a geographical approach to normal IOP interpretation.

\section{ACKNOWLEDGEMENTS}

This project is funded in part by the Noor Vision Correction Centre, and a grant from the Iranian National Research Centre for Medical Sciences. The selection of clusters was based on block enumeration of the national census of 1996 by the Iranian Statistics Centre.

\section{Authors' affiliations}

H Hashemi*, A H Kashi* Farabi Eye Hospital, School of Medicine, Tehran University of Medical Sciences, and Noor Vision Correction Centre, Tehran, Iran
A Fotouhi, K Mohammad, Epidemiology and Biostatistics Department, School of Public Health, Tehran University of Medical Sciences, Iran

*These authors contributed equally to the work.

Competing interests: none declared.

\section{REFERENCES}

1 Drance S. Chronic open angle glaucoma: risk factors in addition to intraocular pressure. Acta Ophthalmol Scand 2001;79:545.

2 Ekstrom C. Incidence studies on open-angle glaucoma. Arch Ophthalmo 2002; 120:522

3 Leske MC, Connell AM, Wu SY, et al. Incidence of open-angle glaucoma: the Barbados Eye Studies. The Barbados Eye Studies Group. Arch Ophthalmol 2001;119:89-95

4 Mitchell P, Smith W, Attebo K, et al. Prevalence of open-angle glaucoma in Australia. The Blue Mountains Eye Study. Ophthalmology 1996; 103:1661-9

5 Sommer A, Tielsch JM, Katz J, et al. Relationship between intraocular pressure and primary open angle glaucoma among white and black Americans. The Baltimore Eye Survey. Arch Ophthalmol 1991;109:1090-5.

6 Bonomi L, Marchini G, Marraffa M, et al. Prevalence of glaucoma and intraocular pressure distribution in a defined population. The Egna-Neumarkt Study. Ophthalmology 1998;105:209-15.

7 Hennis A, Wu SY, Nemesure B, et al. Hypertension, diabetes, and longitudinal changes in intraocular pressure. Ophthalmology 2003;1 10:908-14.

8 Klein BE, Klein R, Linton KL. Intraocular pressure in an American community. The Beaver Dam Eye Study. Invest Ophthalmol Vis Sci 1992;33:2224-8.

9 Tielsch JM, Sommer A, Katz J, et al. Racial variations in the prevalence of primary open-angle glaucoma. The Baltimore Eye Survey. JAMA 1991;266:369-74.

10 Weih LM, Mukesh BN, McCarty CA, et al. Association of demographic, familial, medical, and ocular factors with intraocular pressure. Arch Ophthalmol 2001;119:875-80.

11 Shiose Y, Kitazawa Y, Tsukahara S, et al. Epidemiology of glaucoma in Japan-a nationwide glaucoma survey. Jpn J Ophthalmol 1991;35:133-55.

12 Lee JS, Lee SH, Oum BS, et al. Relationship between intraocular pressure and systemic health parameters in a Korean population. Clin Experiment Ophthalmol 2002;30:237-41.

13 Leske MC, Connell AM, Wu SY, et al. Distribution of intraocular pressure. The Barbados Eye Study. Arch Ophthalmol 1997;115:1051-7.

14 Shields MB. The challenge of screening for glaucoma. Am J Ophthalmol 1995; 120:793-5.

15 Wallace J, Lovell HG. Glaucoma and intraocular pressure in Jamaica. Am J Ophthalmol 1969;67:93-100.

16 Wu SY, Leske MC. Associations with intraocular pressure in the Barbados Eye Study. Arch Ophthalmol 1997;115:1572-6.

17 Fotouhi A, Hashemi H, Mohammad K, et al. The prevalence and causes of visual impairment in Tehran: the Tehran Eye Study. Br J Ophthalmol 2004;88:740-5.

18 Hashemi H, Fotouhi A, Mohammad K. The Tehran Eye Study: research design and eye examination protocol. BMC Ophthalmol 2003;3:8.

19 Attebo K, Ivers RQ, Mitchell P. Refractive errors in an older population: the Blue Mountains Eye Study. Ophthalmology 1999;106:1066-72.

20 Midelfart A, Kinge B, Midelfart S, et al. Prevalence of refractive errors in young and middle-aged adults in Norway. Acta Ophthalmol Scand 2002;80:501-5.

21 Foster PJ, Buhrmann R, Quigley HA, et al. The definition and classification of glaucoma in prevalence surveys. $\mathrm{Br} J$ Ophthalmol 2002;86:238-42.

22 Leske MC. The epidemiology of open-angle glaucoma: a review. Am J Epidemiol 1983;118:166-91.

23 Leske MC, Podgor MJ. Intraocular pressure, cardiovascular risk variables, and visual field defects. Am J Epidemiol 1983;1 18:280-7.

24 Quigley HA, West SK, Rodriguez J, et al. The prevalence of glaucoma in a population-based study of Hispanic subjects: Proyecto VER. Arch Ophthalmol 2001;119:1819-26.

25 Armaly MF. On the distribution of applanation pressure. I. Statistical features and the effect of age, sex, and family history of glaucoma. Arch Ophthalmol 1965;73:11-8

26 Rotchford AP, Johnson GJ. Glaucoma in Zulus: a population-based crosssectional survey in a rural district in South Africa. Arch Ophthalmol 2002; 120:471-8.

27 Shiose $Y$, Kawase Y. A new approach to stratified normal intraocular pressure in a general population. Am J Ophthalmol 1986;101:714-21.

28 Armaly MF. Age and sex correction of applanation pressure. Arch Ophthalmol 1967;78:480-4.

29 Kahn HA, Leibowitz HM, Ganley JP, et al. The Framingham Eye Study. I. Outline and major prevalence findings. Am J Epidemiol 1977;106:17-32.

30 Dielemans I, Vingerling JR, Wolfs RC, et al. The prevalence of primary openangle glaucoma in a population-based study in the Netherlands. The Rotterdam Study. Ophthalmology 1994;101:1851-5.

31 Shiose $Y$. The aging effect on intraocular pressure in an apparently normal population. Arch Ophthalmol 1984;102:883-7.

32 Klein BE, Klein R. Intraocular pressure and cardiovascular risk variables. Arch Ophthalmol 1981;99:837-9.

33 Qureshi IA. Intraocular pressure: a comparative analysis in two sexes. Clin Physiol 1997; 17:247-55.

34 Hiller R, Sperduto RD, Krueger DE. Race, iris pigmentation, and intraocular pressure. Am J Epidemiol 1982;115:674-83. 
35 Mitchell R, Rochtchina E, Lee A, et al. Iris color and intraocular pressure: the Blue Mountains Eye Study. Am J Ophthalmol 2003;135:384-6.

36 Carpel EF, Engstrom PF. The normal cup-disk ratio. Am J Ophthalmol 1981;91:588-97.

37 Varma R, Hilton SC, Tielsch JM, et al. Neural rim area declines with increased intraocular pressure in urban Americans. Arch Ophthalmol 1995; 113:1001-5.
38 Klein BE, Moss SE, Magli YL, et al. Optic disc cupping: prevalence findings from the WESDR. Invest Ophthalmol Vis Sci 1989;30:304-9.

39 Klein BE, Moss SE, Magli YL, et al. Optic disc cupping: four year follow-up from the WESDR. Invest Ophthalmol Vis Sci 1989:30:310-5.

40 Weih LM, Nanjan M, McCarty CA, et al. Prevalence and predictors of openangle glaucoma: results from the visual impairment project. Ophthalmology 2001;108:1966-72.

\section{Video reports}

To view the video reports in full visit our website www.bjophthalmol.com and click on the link to the video reports.

- The presenting features of multiple sclerosis. V J M Barrett, J Walker, J S Elton

- Removal of INTACS: Stepped surgical complexity demonstrated with three cases. $L$ llari, J C McAlister, D S Gartry

- The Nuclear Slide: A novel approach for unleashing the potential of the hydrodissection wave. A Naseri

- Giant pleomorphic adenoma of the lacrimal gland: pre- and post-operative function. A Jain, VI Nehru, U N Saikia, C E E Reddy

- Limbal-sparing lamellar keratoplasty. S L Watson, S Rauz, J Dart

- Bilateral Abducens Neuromyotonia. L H Ospina, N Aui-aree, D P Anderson

- Light to dark physiological variation in irido-trabecular angle width. G M Gazzard, P J Foster, D S Friedman, P T Khaw, S K L Seah

Video Suite: Triamcinolone-assisted vitrectomy

- Triamcinolone-assisted removal of the posterior hyaloid to repair retinal detachment due to macular hole in high myopia. A Ueno, H Enaida, Y Hata, T Nakamura, T Hisatomi, K Fujisawa, T Kubota, T Sakamoto, T Ishibashi

- Triamcinolone acetonide-assisted Epiretinal Membrane Peeling. S D M Chen, CK Patel

- A suture technique to manage a case of severe early flap displacement after laser in situ keratomileusis. L Spadea, P Pantaleoni, G Bianco

- Reconstruction of the Ocular Surface in LOGIC Syndrome. E Moore, V Kumar, $J$ R Ainsworth, S Shah

- Laser Photocoagulation for Posterior Segment Intraocular Parasites. T Prabriputaloong, S Asawaphureekorn

- Feeder Vessel Treatment with High Speed ICG Angiography. D Stanescu-Segall, $G$ Coscas, F Coscas, G Soubrane

- Endoscopy to aid anterior segment surgery. J E Moore, A Sharm

- Penetrating ocular injury due to a fish hook: Surgical removal. SDM Chen, D Chiu, C K Patel

- Retinal Ganglion Cell Axon Response to Guidance Molecules. S F Oster and DW Sretavan

- Marin-Amat Syndrome. A Jogiya, C Sandy

- Excision of subcutaneous Dirofilariasis of the eyelid. D Mallick, T P Ittyerah

- Thixotropy: a novel explanation for the cause of lagophthalmos after peripheral facial nerve palsy. M Aramideh, J H T M Koelman, P P Devriese, F VanderWerf, J D Speelman

- Surgical revision of leaking filtering blebs with an autologous conjunctival graft. $K$ Taherian, A Azuara-Blanco

- Dipetalonema Reconditum in the human eye. THuynh, J Thean, R Maini 